Current psychology letters

\title{
Age Differences in the Organization and Acquisition-Forgetting Processes in a Multi-Free- Recall Task
}

Hélène Sauzéon, Bernard Claverie and Bernard N'Kaoua

\section{CpenEdition}

\section{Journals}

Electronic version

URL: http://journals.openedition.org/cpl/1012

DOI: $10.4000 / \mathrm{cpl} .1012$

ISSN: $1379-6100$

Publisher

Centre PsyCLÉ

\section{Electronic reference}

Hélène Sauzéon, Bernard Claverie and Bernard N'Kaoua, « Age Differences in the Organization and Acquisition-Forgetting Processes in a Multi-Free-Recall Task », Current psychology letters [Online], 18, Vol. 1, 2006 | 2006, Online since 30 March 2006, connection on 08 September 2020. URL : http:// journals.openedition.org/cpl/1012 ; DOI : https://doi.org/10.4000/cpl.1012

This text was automatically generated on 8 September 2020

(C) All rights reserved 


\title{
Age Differences in the Organization and Acquisition-Forgetting Processes in a Multi-Free-Recall Task
}

\author{
Hélène Sauzéon, Bernard Claverie and Bernard N'Kaoua
} require multiple study-test trials to master new material. It has usually been reported that more trials are required for older adults to reach the same level of performance as younger adults (Delbecq-Derouesné \& Beauvois, 1989; Witte et al., 1990; Kausler, 1994; Dunlosky \& Salthouse, 1996; Kahana \& Wingfield, 2000; Davis et al., 2001).

One of the main issues in the understanding of human learning is the relationship between learning and organization processes. Numerous studies have highlighted two major organizational components that affect the structure of memory retrieval. In selfinitiated memory retrieval, participants rely both on preexisting knowledge of such semantic relationships as may be present in a list of items (semantic memory) and on newly formed contextual associations among list items (episodic memory). These two organizational factors are expressed by the output order in free recall. Semantic memory describes a learner's tendency to recall categorically related words in clusters, even when the items are presented in random order (Bousfield, 1953; Romney et al., 1993; Kahana \& Winfield, 2000). Episodic memory leads subjects to develop a subjective organization of a list of unrelated items (items not constrained by preexisting categorical or associative relations), as revealed by the correlation of output order in successive recall trials (Tulving, 1962; Sternberg \& Tulving, 1977; Howard \& Kahana, 1999). In fact, it has classically been observed that all the kinds of organization measures (semantic and subjective) tend to increase regularly with the increasing 
number of items recalled across the learning trials. Furthermore, Kahana and Wingfield (2000) showed that the relation between semantic organization and learning for related materials remained invariant during normal aging, even if age-related differences have been observed in mnemonic abilities. In other words, for these authors, the learning process in old adults may be slowed across trials but its essential form remains unchanged. Nevertheless, the question of whether older adults generally show less organization in their learning and recall has been somewhat controversial in literature on aging. For example, age related differences are often observed in subjective organization measurements (episodic memory) (Witte et al., 1990; 1993; Hultsch, 1974; Light, 1991; Kausler, 1994; Stuss et al., 1996), but not, or only slightly, in semantic organization measurements based on the use of preexisting knowledge (semantic memory) (Park et al., 1989; Luszcz, et al., 1990; Bäckman \& Larsson, 1992; Bäckman \& Wahlin, 1995; Burack \& Lachman, 1996; Kahana \& Wingfield, 2000; Zacks \& Hasher, 2000; Sauzéon et al., 2001). Consequently, the first aim of the present study was to verify whether age affected the episodic component of organizational processing (i.e., subjective organization) but not its semantic component (i.e., semantic organization).

In addition, organizational processing is supposed to reduce inter-trial forgetting (Klein et al., 1989; Burn, 1993; Widner et al., 2000). Thus, once an item has been retrieved from memory in one trial it is likely to be retrieved in the next if it is part of an organized retrieval network. Retaining items already acquired is not sufficient to improve free-recall performance in learning tasks, subjects must also acquire items not recalled in previous trials. The loss of access to items from one trial to the next (lost access), as well as the gains in access to items from one trial to the next (gained access), are easily measurable using trial-by-trial performance analysis (Tulving, 1964; Blachstein, Vakil, \& Hoofien, 1993; Dunlosky \& Salthouse, 1996): Gained access measures the proportion of items recalled in trial $n+1$ that were not recalled in trial $n$, whereas lost access measures the proportion of items not recalled in trial $n+1$ that were recalled in trial $n$. Access gains reflect the effectiveness of acquisition processes whereas losses indicate inter-trial forgetting (Bachstein, Vakil, \& Hoofien, 1993; Dunlosky \& Salthouse, 1996). Therefore, organizational processing may have a significant impact on lost access, insofar as it prevents inter-trial forgetting. Consequently, lost access is expected to be strongly related to organizational measurements whereas these have less impact on gained access. Obviously, there should be a stronger relationship between lost access and organizational measurements when the material promotes organizational processing, e.g. lists of related words, compared with lists of unrelated words (Einstein \& Hunt, 1980; Hunt \& Seta, 1984; Hunt \& Einstein, 1981; Alba et al. 1980; Hanson et Hirst, 1988).

7 In analyzing age-related differences in a multi-trial free-recall task of unrelated lists, Dunlosky and Salthouse (1996) showed that gained access decreased considerably and lost access increased slightly with age. Thus, they considered that the aging decline in gained access played a larger role in mediating age-related differences in learning than lost access. Moreover, they observed a greater negative correlation between age and gained access than between age and lost access. In this case, according to our assumption about the relationship between lost access and organizational processing, the age-related difference in learning is more due to a decline in effective acquisition than in organizational processing. However, this study used a list of unrelated words, which is known to promote organizational processing less than a related list. Consequently, it remains to be investigated whether the greater impact of gained over 
lost access in age-related differences in learning holds true, even when the material promotes organizational processing, e.g. related lists.

In summary, we initially examined age-differences in the semantic and episodic components of organizational processing (i.e. semantic vs. subjective organization measures) during multi-trial free recall. Secondly, we investigated the relationship between organizational processing and gained/lost access during a multi-trial free recall task using related and unrelated word lists. In addition, the impact of aging on gained and lost access was assessed as a function of list structure (related vs. unrelated), as well as the relationship between losses and organizational processing.

METHOD

Participants.

10 They consisted of one sample of 44 adults divided into two age groups (Table 1): 22 young adults aged 20-39 years and 22 old adults aged 65-89 years. All participants were volunteers not living in institution, whose native language was French. None of the participants had history of neurological or psychiatric disorders, head injuries and/or alcoholism, and the elderly reported excellent health and good hearing. Moreover, subjects selected for the both groups has similar education levels $[\underline{F}(1,42)=0.03, \underline{p}>.800]$. The vocabulary subtests of the WAIS-R (Wechsler Adult Scale-Revised, Wechsler, 1981; maximum score $=20$ ) were taken by both groups and showed a difference in favor of the older group $[\underline{\mathrm{F}}(1,42)=4.39, \mathrm{p}<.05]$. The MMSE (Mini-Mental-State-Examination, Folstein \& al., 1975; maximum score $=30$ ) was administered only to the subjects aged over 65 years.

Table 1. Subject characteristics

\begin{tabular}{lccccc}
\hline & Age & Sex & $\begin{array}{c}\text { Education } \\
\text { (years) }\end{array}$ & $\begin{array}{c}\text { WAIS-R } \\
\text { Vocabulary test }\end{array}$ & MMS \\
\hline Young group $(n=22)$ & & & & & \\
$M$ & 27.32 & 15 women & 11.72 & 10.45 & \\
$S D$ & 6.69 & 7 men & 1.98 & 2.06 & \\
Old group $(n=22)$ & & & & & \\
$M$ & 74.36 & 16 women & 11.59 & 12.00 & 28.87 \\
$S D$ & 3.87 & 6 men & 3.09 & 2.77 & 1.11 \\
\hline
\end{tabular}

Materials.

12 Two different 20-word lists were constructed with different degrees of organization (unrelated vs. related words). A total of 40 concrete disyllabic words (i.e., "ba-teau") was selected to build two lists with the same frequency of utilization (from the Brulex database; Content et al., 1990) [means and ANOVA on the measures of word frequency: $\mathrm{m}_{\text {unrelated/frequent }}=2195.71, \mathrm{SD}=1377.56 ; \mathrm{m}_{\text {related/frequent }}=2551.43, \mathrm{SD}=2100.23$; list effect: $p>.500]$. The related list was composed of items from four different categories (clothes; musical instruments; vehicles; insects), with 5 exemplars per category [ANOVA on the measures of word frequency per category: Category effect: $p>.500]$. The order of word lists was counterbalanced among subjects. During the study phase, the words were presented orally, one word every four seconds. Subsequently, subjects perform the free recall task.

Procedure

13 Before each memory test, the experimenter informed subjects that the task consisted of a presentation of words followed by free recall, and that all words were to be remembered. Subjects were also informed that this procedure would be repeated three times. Performance was assessed in free recall. To assess clustering processes (semantic 
and subjective clustering across trials), only performances obtained after the second free recall tests were analyzed in terms of number of categories and words per category recalled; ARC scores (semantic clustering: Adjusted Ratio of Clustering; Roenker et al., 1971), and PF scores (Subjective clustering across free-recall trials: Pairwise Frequency; Anderson \& Watt, 1969; Sternberg \& Tulving, 1977). Gained and lost access scores were computed. Gained access was the total number of words gained from one trial $\left(\right.$ Trial $\left._{n}\right)$ to the next $\left(\operatorname{Trial}_{n+1}\right)$. This measure reveals the efficiency of acquisition processes. Lost access was the total number of words lost from one trial $\left(\operatorname{Trial}_{n}\right)$ to the next $\left(\operatorname{Trial}_{n+1}\right)$. This measure reveals inter-trial forgetting.

RESULTS

All reported effects from the overall statistical analyses were significant at least $p<.05$.

Number of words recalled

Performances obtained under all free recall conditions (Table 2) were analyzed with a 2 (Age: young and old) $\times 2$ (List: unrelated and related) $\times 2$ (Trial: trial 2 and 3) mixed ANOVA, with repeated measurements on the last two factors.

The ANOVA revealed that the three factors had significant effects: Age $[F(1,42)=49.46$; $\left.\mathrm{MS}_{\mathrm{e}}=2233.69\right]$; List $\left[F(1,42)=29.48 ; \mathrm{MS}_{\mathrm{e}}=198.69\right]$; Trial $\left[F(1,42)=132.81 ; \mathrm{MS}_{\mathrm{e}}=238.78\right]$. For interactions including the age factor, only the three-way interaction was significant $\left[F(1,42)=4.06 ; \mathrm{MS}_{\mathrm{e}}=5.46\right]$ : The old group benefited more from rehearsals for related than unrelated lists, contrary to the young group whose scores for unrelated lists improved more than those for related lists (Table 2).

Clustering PF performances

The PF Scores obtained (Table 2) were analyzed with a 2 (Age) x 2 (Type of List) x 2 (Inter-Trial: Inter-trial 1-2; Inter-trial 2-3) mixed. The ANOVA revealed three simple factor effects as fallows: Age $\left[F(1,42)=27.98 ; \mathrm{MS}_{\mathrm{e}}=145.43\right]$; Inter-Trial $[F(1,42)=29.62$; $\left.\mathrm{MS}_{\mathrm{e}}=43.35\right]$; and Type of List $\left[F(1,42)=4.41 ; \mathrm{MS}_{\mathrm{e}}=11.95\right]$. Only one two-way interaction involving the age factor was significant: The age differences between $P F$ scores increased across trials [Age*Inter-Trial: $F(1,42)=16.42 ; \mathrm{Ms}_{\mathrm{e}}=24.03$ ].

Clustering ARC performances

18 An ARC score of 1.0 indicates perfect clustering, whereas 0 is equal to random levels. The ARC scores obtained in the related list condition (Table 2.) were analyzed with a 2 (Age) $x 2$ (Trial: trial 2 and 3) mixed ANOVA. None of the effects were significant, except the trial effect, which showed an increase in ARC scores across the trials $[F(1,42)=4.72$; $\mathrm{MS}_{\mathrm{e}}=0.59$.

Number of Categories recalled A 3 (Age) x 2 (Frequency) x 2 (Trial: trial 2 and 3) ANOVA applied to the number of categories recalled in the related list condition revealed only an Age effect $\left[F(1,42)=10.71 ; \mathrm{MS}_{\mathrm{e}}=6.01\right]$. This indicated that the old group recalled fewer categories than their young counterparts.

Number of words per category recalled

21 A 2 (Age) $\times 2$ (Trial: trial 2 and 3) ANOVA applied to the number of words per category recalled in the related list condition revealed) that the old group performed less well than the younger one $\left[F(1,42)=42.35 ; \mathrm{MS}_{\mathrm{e}}=63.49\right]$; and the number of words per category increased across trials $\left[F(1,42)=35.05 ; \mathrm{MS}_{\mathrm{e}}=5.71\right]$. 
Gained access

Gained-word performances (Table 2) were analyzed with a 2 (Age) x 2 (List) x 2 (InterTrial: Inter-trial 1-2 and Intertribal 2-3) mixed ANOVA, with repeated measurements on the last two factors. The analysis revealed one simple main effect and two interactions involving the age factor: The simple effect indicated that the old group gained less than young [Age: $\left.F(1,42)=3.98 ; \mathrm{MS}_{\mathrm{e}}=20.45\right]$; interaction with the inter-trial factor revealed that the young group gained more words than the old one from trial 1 to trial 2, while the old group gained nearly as much as the young group from trial 2 to trial 3 [Age $x$ Inter-trial: $\left.F(1,42)=15.35 ; \mathrm{MS}_{\mathrm{e}}=54.57\right]$. The interaction with the material factor indicated that the young group gained more words from unrelated than related lists, whereas the old group gained more words from related than unrelated lists [Age x Material: $\left.F(1,42)=3.80 ; \mathrm{MS}_{\mathrm{e}}=13.09\right]$.

Loss Access

Lost-word performance under all conditions (Table 2) was analyzed with a 2 (Age) x 2 (List) x 2 (Inter-trial) mixed ANOVA, with repeated measures on the last two factors. The ANOVA revealed only two interaction effects involving the age factor. The first indicated that the young group lost more words from unrelated than related lists, while the reverse effect was observed for the old group [Age x Material: $F(1,42)=3.91$; $\left.\mathrm{MS}_{\mathrm{e}}=7.36\right]$. The second revealed that the young group lost more words between trials 1 and 2 than trials 2 and 3 , whereas the reverse effect was observed for old group [Age $\mathrm{x}$ Inter-trial: $\left.F(1,42)=3.93 ; \mathrm{MS}_{\mathrm{e}}=5.11\right]$.

24 In summary, younger adults recalled more categories, more words per category, and more words altogether. These results are consistent with those obtained by Sanders et al. (1980) and Witte et al. (1993). The interaction effects including the age factor indicate that related lists enhanced the benefit of rehearsal for the old adults. In terms of clustering measurements, all age groups had similar ARC scores but the PF scores for the old group decreased gradually across trials, irrespective of the type of list (related vs. unrelated). This is in agreement with numerous aging studies showing that age differences are more often observed in subjective organization measurements (PF score) than those based on preexisting knowledge (ARC score) (Hultsh, 1974; Witte et al., 1990; 1993; Light, 1991; Kausler, 1994; Zacks \&Hasher, 2000; Sauzéon et al., 2001).

Furthermore, young adults gained more words from unrelated lists than old adults. Lost access using related lists was greater for old adults than young adults.

Table 2. Performances for free-recall, Gain and Loss, PF and ARC scores, number of categories recalled and number of words per category recalled as a function of age. 


\begin{tabular}{|c|c|c|c|c|c|}
\hline \multirow[b]{2}{*}{ Group } & & \multicolumn{2}{|c|}{ Unrelated Lists } & \multicolumn{2}{|c|}{ Related Lists } \\
\hline & & Trials 2 & Trials 3 & Trials 2 & Trials 3 \\
\hline & & & & & \\
\hline \multirow[t]{2}{*}{ Young } & $\mathrm{M}$ & 11.27 & 14.27 & 14.63 & 16.59 \\
\hline & SD & 4.38 & 4.54 & 4.68 & 4.32 \\
\hline \multirow[t]{3}{*}{ Old } & $\mathrm{M}$ & 5.36 & 7.36 & 6.59 & 8.95 \\
\hline & SD & 1.70 & 2.21 & 2.79 & 3.72 \\
\hline & & \multicolumn{4}{|c|}{ ARC Score } \\
\hline \multirow[t]{2}{*}{ Young } & M & & & 0.46 & 0.63 \\
\hline & SD & • & - & 0.39 & 0.25 \\
\hline \multirow[t]{3}{*}{ Old } & $\mathrm{M}$ & - & . & 0.37 & 0.53 \\
\hline & SD & & & 0.62 & 0.37 \\
\hline & & \multicolumn{4}{|c|}{ Categories Recalled } \\
\hline \multirow{2}{*}{ Young } & M & & & 3.86 & 3.95 \\
\hline & SD & - & - & 0.47 & 0.21 \\
\hline \multirow[t]{3}{*}{ Old } & M & - & - & 3.32 & 3.45 \\
\hline & SD & & & 0.71 & 0.85 \\
\hline & & \multicolumn{4}{|c|}{ PF Score } \\
\hline \multirow[t]{2}{*}{ Young } & M & 1.25 & 2.90 & 1.88 & 3.70 \\
\hline & SD & 1.30 & 2.84 & 1.51 & 2.39 \\
\hline \multirow{3}{*}{ Old } & $\mathrm{M}$ & 0.23 & 0.67 & 0.74 & 0.82 \\
\hline & SD & 0.56 & 0.82 & 0.93 & 1.27 \\
\hline & & \multicolumn{4}{|c|}{ Gain } \\
\hline \multirow[t]{2}{*}{ Young } & $\mathrm{M}$ & 4.86 & 3.95 & 4.77 & 2.77 \\
\hline & SD & 2.62 & 2.15 & 2.16 & 1.77 \\
\hline \multirow[t]{2}{*}{ Old } & $\mathrm{M}$ & 2.95 & 3.41 & 3.09 & 4.18 \\
\hline & SD & 1.29 & 1.91 & 1.97 & 1.50 \\
\hline \multirow{3}{*}{ Young } & & & & & \\
\hline & M & 1.22 & 1.22 & 1.00 & 0.86 \\
\hline & SD & 1.97 & 0.92 & 1.85 & 0.89 \\
\hline \multirow[t]{2}{*}{ Old } & $\mathrm{M}$ & 0.66 & 1.36 & 1.27 & 1.82 \\
\hline & SD & 0.83 & 1.00 & 1.12 & 1.36 \\
\hline
\end{tabular}

Correlational analysis by age group was carried out to establish the relationship between organizational processing and lost access (Table 3). The PF clustering measurements for young and old adults correlated significantly with loss but not with gain scores. Specifically, PF performances were negatively correlated with loss scores in the related list condition and, and values were higher for the young than for the old group.

Table 3: Correlation value by age group for gain or loss scores with clustering measurements (ARC and PF Scores) $\left({ }^{*} \mathrm{p}<.05 ;{ }^{* *} \mathrm{p}<.01\right)$.

\begin{tabular}{|c|c|c|c|c|}
\hline \multirow[b]{2}{*}{ Group } & \multicolumn{2}{|c|}{ Unrelated List } & \multicolumn{2}{|c|}{ Related List } \\
\hline & Inter-Trials 1-2 & Inter-Trials 2-3 & Inter-Trials 1-2 & Inter-Trials 2-3 \\
\hline & \multicolumn{4}{|c|}{ PF score/Gain } \\
\hline Young & .02 & -.22 & .22 & -.11 \\
\hline Old & -14 & -.13 & .25 & 25 \\
\hline & \multicolumn{4}{|c|}{ PF score/Loss } \\
\hline Young & .007 & -.25 & $-46^{*}$ & $-60^{* 8}$ \\
\hline Old & .24 & -.17 & $-47 *$ & -39 \\
\hline & \multicolumn{4}{|c|}{ ARC score/Gain } \\
\hline Young & & & .03 & $-43^{2}$ \\
\hline Old & & & .02 & -.35 \\
\hline & \multicolumn{4}{|c|}{ ARC score/Loss } \\
\hline Young & & & $-.42 *$ & -.35 \\
\hline Old & & & .15 & .11 \\
\hline
\end{tabular}

Discussion

Regarding the number of words recalled, rehearsal enabled the old subjects to improve their memory performance, as already shown by numerous aging studies (DelbecqDerouesné \& Beauvois, 1989; Witte et al., 1990; Kausler, 1994; Dunlosky \& Salthouse, 1996; Kahana \& Wingfield, 2000; Davis et al., 2001). In addition, the improvement was 
greater for related than unrelated lists. As a result, old adults had less difficulty when the material involved the semantic component of organizational processing. This is borne out by the fact that there were no age-related differences in the ARC scores. The unchanged ARC score with age is well documented (Park et al., 1989; Luszcz, et al., 1990; Bäckman \& Larsson, 1992; Bäckman \& Wahlin, 1995; Burack \& Lachman, 1996; Kahana \& Wingfield, 2000; Sauzéon et al., 2001), showing that old subjects are good at organizing the related words they remember. Therefore, organizational processes based on preexisting knowledge do not change in their essential form, as proposed by Kahana and Wingfield (2000). The unchanged ARC scores contrasted with impairment of subjective organization (PF score) for both related and unrelated lists, although this is widely reported in aging literature (Hultsch, 1974; Witte et al., 1990). This suggests that age differences in learning related and unrelated lists result mainly from difficulty in forming contextual associations that maintain item order within clusters in the trials. Thus, old participants were able to use the semantic relations presented in the lists (preserved ARC score), but were less inclined to form contextual associations among items (declined PF score). In other words, the episodic component of organizational processing was affected by aging while the semantic component remained intact.

In terms of items gained and lost, the results for unrelated lists revealed great age differences in gains and little or no difference in losses, in agreement with findings by Dunlosky and Salthouse (1996). Thus, as previously shown, gained access apparently plays a more important role in the age-related difference in learning unrelated lists than lost access. In contrast, for related lists, age-related differences concerned losses but not gains, indicating that lost access plays a greater role than gained access. Consequently, the present study clearly added that the importance of acquisition or forgetting in the age-related difference in learning depends on the structure of the material and, by extension, on the processing facilitated by the material. If the material encourages organizational processing, e.g. related lists, then forgetting is the main factor in learning decline with age whereas, if this is not the case, e.g. unrelated lists, then acquisition is the major factor. This supports our assumption of the importance of the relationship between inter-trial forgetting and organizational processing. Our assumption is also sustained by correlational analysis results, indicating that these organizational processes reduce inter-trial forgetting. First, the greatest increase in scores did not correlated with the clustering measurements (ARC and PF), irrespective of material and age factors. In contrast, loss scores correlated with clustering measures, particularly PF scores. Second, the values of these correlations differed according to both material and age. Indeed, when the material encouraged organizational processing (related list), losses correlated negatively with PF scores, but this was not the case with unrelated lists. So, as expected, lost access was conversely related to the involvement of organizational processing in the learning task. Furthermore, as these significant negative correlations concerned PF scores, it was probably the episodic rather than the semantic component of organizational processing that played a major role in preventing inter-trial forgetting. In this context, the decrease in correlation values between PF and loss measurements for related lists with age may indicate that the decline in the episodic component of organizational processing with age increased the inter-trial forgetting of related words. This may explain why the old subjects' learning performance was affected, even if they benefited from the semantic organization of related lists. 
31 Several conclusions may be drawn from the overall findings in the multi-trial free recall. Firstly, old adult benefited more from the facilitation of organizational processing via related lists in successive trials. This effect may be due to the preservation of the semantic organization component with age that enables old subjects to use their knowledge to organize and recall related words according to their semantic relationships. Secondly, the examination of access gains and losses revealed that the episodic organization component was particularly involved in inter-trial forgetting. This provides additional information on age-related differences, indicating that acquisition plays a considerable role in learning unrelated words while forgetting is more involved in learning related words. In addition, as the episodic organization component may prevent the forgetting of related lists, its decline with age may explain why old adults forgot more between trials, although their performance increased, probably due to the preserved semantic component of organizational processing. Nevertheless, further research is required to provide a complete characterization of the relationships between organizational processing and lost/gained access to enhance our understanding of the effect of aging on learning capacities.

\section{BIBLIOGRAPHY}

Alba, J.W., Chromiak, W., Hasher, L., \& Attig, M.S. (1980) Journal of Experimental Psychology: Human Learning and Memory, 6, 4, 370-378.

Anderson, R.C. \& Watt, G.H. (1969) Bidirectional associations in multi-trial free recall. Psychonomic Science, 15, 288-289

Bäckman, L. \& Larsson, M. (1992) Recall of organizable words and objects in adulthood: Influences of instructions, retention interval, and retrieval cues. Journal of Gerontology:, 47, 4, P273-P278.

Bäckman, L. et Wahlin, A. (1995) Influences if item organizability and semantic retrieval cues on word recall in very old age. Aging and Cognition, 2, 4, 312-325.

Blachstein, H., Vakil, E. \& Hoofien, D. (1993) Impaired learning in patients with closed-head injuries: An analysis of components of the acquisition process. Neuropsychology, 7, 530-535.

Bousfield, W.A. (1953) The occurrence of clustering in the recall of randomly arranged associates. Journal of General Psychology, 49, 229-240.

Burack, O.R. \& Lachman, M.E. (1996) The effect of list-making on recall in young abd elderly adults. Journal of Gerontology: Psychological Sciences, 51B, 226-233.

Burn, D.J. (1993) Item gains and losses during hypermnesic recall: Implications for the itemspecific-relational information distinction. Journal of Experimental Psychology: Learning, Memory, \& Cognition, 19, 163-173.

Content A., Mousty, P., Radeau, M. (1990) Brulex une base de données lexicales informatisées pour le Français parlé et écrit. L'Année Psychologique, 90, 551-566. 
Davis, H.P., Trussell, L.H. \& Klebe, K.J. (2001) A ten-year longitudinal examination of repetition priming, incidental recall, free recall, and recognition in young and elderly. Brain \& Cognition, 46, 99-104.

Delbecq-Derouesné, J. \& Beauvois, M. (1989) Memory processes and aging: A defect of automatic rather than controlled processes? Archives of Gerontology and Geriatrics, Suppl., 1, 121-150.

Dunlosky, J. \& Salthouse, T.A. (1996) A decomposition of age-related differences in multitrial free recall. Aging, Neuropsychology, and Cognition, 3, 1, 2-14.

Einstein, G.O., \& Hunt, R.R. (1980) Level of processing and origination: additive effects of individual item and relational processing. Journal of Experimental Psychology: Human Learning and Memory, 6, 588-598.

Folstein, M.F., Folstein, S.E., \& McHugh, P.R. (1975) “ Mini-mental state: ” A practical method for grading the cognitive state of patients for the clinician. Journal of Psychiatric Research, 12, 189-198.

Hanson, C. \& Hirst, W. (1988) Frequency encoding of token and type information. Journal of Experimental Psychology: Learning, Memory, and Cognition, 14, 2, 289-297.

Howard, M. \& Kahana, M.J. (1999) Contextual variability and serial position effects in free recall. Journal of Experimental Psychology: Learning, Memory \& Cognition, 25, 923-941.

Hultsch, D.F. (1974) Learning to learn in adulthood. Journal of Gerontology, 29, 302-308.

Hunt, R.R. \& Einstein, G. (1981) Relational and item-specific information in memory:. Journal of Verbal Learning and Verbal Behavior, 20, 497-514.

Hunt, R.R. \& Seta, C.E. (1984) Category size effects in recall: The roles of relational and individual item information. Journal of Experimental Psychology: Learning, Memory, and Cognition, 10, 454-464.

Kahana, M.J. \& Winfield, A. (2000) A functional relation between learning and organization in free recall. Psychonomic Bulletin \& Review, 7, 516-521.

Kausler, D.H. (1994) Learning and memory in normal aging. San Diego: Academic Press.

Klein, S.B., Loftus, J., Kihlstrom, J.F. \& Aseron, R. (1989) Effects of item specific and relational information on hypermnesic recall. Journal of Experimental Psychology: Learning, Memory \& Cognition, 15, 1192-1197.

Light, L.L. (1991). Memory and aging: Four hypotheses in search of data, Annual Review of Psychology, 42,33-376.

Luszcz, M., Roberts, T., \& Mattiske, J. (1990) Use of relational and item-specific information in remembering by older and young adults. Psychology and Aging, 5, 242-249.

Park, D.C., Smith, A.D., Dudley, W.N., \& Lafronza, V.N. (1989) Effects of age and divided attention task presented during encoding and retrieval on memory. Journal of Experimental Psychology: Learning, Memory, and Cognition, 15, 6, 1185-1191.

Roenker, D.L., Thompson, C.P., \& Brown, S.C. (1971) Comparison of measures for the estimation of clustering in free recall. Psychological Bulletin, 76, 1, 45-48.

Romney, A.K., Brewer, D.D., \& Batchelder, W.H. (1993) Predicting clustering from semantic structure. Psychological Science, 4, 28-34.

Salthouse, TA. \& Dunlosky, J. (1995) Analyses of adult age differences in associative learning. Zeischrigt für Psychology.;203, 351-60. 
Sanders, R.E., Murphy, M.D., Schmitt, F.A., \& Walsh, K.K. (1980) Age differences in free recall rehearsal strategies. Journal of Gerontology, 35, 550-558.

Sauzéon, H., N'Kaoua, B. \& Claverie, B. (2001) Self-generated category cue effect on organizational processing in three different age groups. Current Psychology Letters: Behavior, Brain, and Cognition, 2, 65-78.

Sternberg, R.J. \& Tulving, E. (1977) The measurment of subjective organization in free recall. Psychological Bulletin, 84, 3, 539-556.

Stuss, D.T., Craik, F.I.M., Sayer, L., Franchi, D., \& Alexander, M.P. (1996) Comparison of older peaolple and patients with frontal lesions: Evidence from word list learning. Psychology \& Aging, 11, 387-395.

Tulving, E. (1962) Subjective organization in free recall of "unrelated" words. Psychological Review, 69, 344-354.

Tulving, E. (1964) Intratrial and inter-trial retention: Notes towards a theory of free recall verbal learning. Psychological Review, 71, 219-237.

Wechsler, D. (1981). Wechsler Adult Intelligence Scale Revised (French translation) Paris, Eds. du Centre de Psychologie Appliquée.

Widner, R.L., Otani, H. \& Smith, A.D. (2000) Hypermnesia: Age-related differences between young and older adults. Memory \& Cognition, 28, 556-564.

Witte, K.L., Freund, J.S., \& Brown-Whistler, S. (1993) Adult age differences in free recall and category clustering. Experimental Aging Research, 19, 15-28.

Witte, K.L., Freund, J.S., \& Sebby, R.A. (1990) Age differences in free recall and subjective organization. Psychology and Aging, 5, 307-309.

Zacks, R.T., Hasher, L., \& Li, K.Z.H. (2000) Human memory. In F.I.M. Craik \& T. Saltouse (Eds.) Handbook of Aging and Cognition. Lawrence Erlbaum Associates, New Jersey.

\section{ABSTRACTS}

This study addressed the relationships between organizational processing and acquisition / forgetting processes. Twenty-two young and 22 older adults were tested using three study and free-recall test trials involving related or unrelated words. Performances in all trials were analyzed in terms of the number of words recalled, clustering measures (PF and ARC), and words gained and lost (Dunlosky \& Salthouse, 1996). For material manipulation, the older group benefited more from repeated trials when the words were related, indicating that organizational processes are less spontaneously initiated with age. This finding is confirmed by a significant age effect on the episodic component of organizational processing (PF clustering scores), but no age effect on its semantic component (ARC scores). For gain and loss scores, gains (acquisition processes) played a major role in age differences in the learning of unrelated words while losses (forgetting processes) had more impact on the learning of related words. In addition, the correlational results indicated that the episodic organization component (PF scores) seemed to prevent item losses in the younger group, whereas it was less salient in the older adults.

Cette étude s'adresse aux relations entre les processus d'organisation et les processus d'acquisition et d'oubli.Vingt-deux participants jeunes et 22 participants âgés ont été soumis à deux tâches de rappels libres successifs (3 présentations suivies chacune d'un rappel) variant par la nature du matériel à mémoriser (liste de mots reliés vs. non reliés). Les performances 
obtenues à chaque essai de rappel ont été analysées en termes de nombre de mots rappelés, de mesures d'organisation (scores PF et ARC) et de gains / pertes (mots gagnés ou perdus entre deux essais) (Dunlosky \& Salthouse, 1996). Les résultats indiquent que les essais successifs sont plus bénéfiques pour les âgés lorsque le matériel est relié révélant ainsi une difficulté à auto-initier les processus d'organisation. Aussi, cette difficulté intéresse principalement la composante épisodique des mécanismes d'organisation (effet significatif de l'âge sur les scores PF) plutôt que la composante sémantique (absence d'effet d'âge sur les scores ARC). De plus, les résultats portant sur les gains et les pertes indiquent que les mécanismes d'acquisition jouent un rôle plus important dans les différences liées à l'âge dans l'apprentissage d'un matériel non-relié alors que les processus d'oubli contribuent plus aux difficultés d'apprentissage d'un matériel relié. Enfin, la composante épisodique des mécanismes d'organisation semble jouer un rôle préventif contre l'oubli (corrélation négative entre les pertes et les scores PF) chez les participants jeunes, et ce rôle est diminué avec l'âge.

INDEX

Keywords: Aging, Learning, Acquisition process, Forgetting process

\section{AUTHORS}

HÉLÈNE SAUZÉON

Laboratoire de Sciences Cognitives (E.A. 487) -

BERNARD CLAVERIE

Université Victor Segalen - Bordeaux 2

BERNARD N'KAOUA

146 rue Léo Saignat- BP40 